\title{
The exploration on the reform of production practice for photoelectric specialty
}

Ling-ling Wu, Ming Gao, Hai-bin Chen, Chan-lao Liu

Ling-ling Wu, Ming Gao, Hai-bin Chen, Chan-lao Liu, "The exploration on the reform of production practice for photoelectric specialty," Proc. SPIE 10452, 14th Conference on Education and Training in Optics and Photonics: ETOP 2017, 1045250 (16 August 2017); doi: 10.1117/12.2269777

SPIE Event: 14th Conference on Education and Training in Optics and Photonics, ETOP 2017, 2017, Hangzhou, China 


\title{
The exploration on the reform of production practice for photoelectric specialty \\ Ling-ling $\mathrm{Wu}^{*}$, Ming Gao, Hai-bin Chen, Chan-lao Liu \\ Institute of Optoelectronic Engineering, Xi'an Technological University, Xi'an 710021, China
}

\begin{abstract}
During the undergraduate course of students of photoelectric specialty, production practice is a very important step. Aiming at solving the disadvantage of the traditional production practice procedure, consulting the actual situation of production practice in recent years, some exploration was carried out to reform the production practice for the photoelectric specialty through the combination of application of practice base off campus and construction of practice base on campus, which has many models to satisfy the requirements of the diversity of photoelectric specialty and high quality innovative talents. All the facts proved that the practice quality is improved obviously.
\end{abstract}

Keywords: Photoelectric specialty, production practice, practice base

\section{INTRODUCTION}

\subsection{Significance of practice and training}

Internship is an important part of on-campus practices for undergraduate students of optoelectric specialty, which is a good change for them to widen their vision, and recognize development level of domestic optoelectronic industry and it is also an important way for the engineering training of undergraduate students ${ }^{[1-3]}$.

With market globalization, the competition of talents is increasingly fierce, which greatly enhances the requirement on the cultivation of talents. Firstly, we need to cultivate graduates with profound theoretical basis, and more importantly, we need to develop the students' ability on, problem analyzing and solving, practical operation, to meet the requirements from global competition environment.

Currently, teaching links of engineering specialties in universities of our country for the improvement of students' practical ability, except for a limited number of experiments and production practices, experimental training changes for undergraduates are very few. Therefore, it is of great significance to discuss how to grasp the teaching link of the production practice and training.

\subsection{Present situation of campus internship}

Due to the change of social economic environment, companies and enterprises are facing more and more fierce competition at home and abroad, some companies and enterprises refuse or set restricts on off-campus internship of undergraduates because of technical secrets, intellectual property rights protection, students' safety, influence enterprise production efficiency, etc.

In addition, with the enrollment expansion of universities, for the large number of students and very limited available resources for the internship, enterprises are forced to adopt the rotation means, internship time for undergraduates is compressed into a very limited period, which greatly downgraded teaching effect of the off-campus internship.

On the other hand, during the whole internship period, students cannot involve in the specific production processes, students can only observe and record fabrication processes by looking up factory process documents, and have no opportunity of actual participations or practices. As a result, current internship methods contribute little to the improvement of students' practical ability. At the same time, because of large number of students and few participations, instead of providing guidance, teacher's primary responsibility becomes maintaining discipline in order to avoid accidents, which will result increasing of management difficulties.

Generally speaking, production practices of engineering specialties are facing many difficulties and problems. Under conventional teaching system, the implement of the teaching link of internship becomes increasingly difficult, which has been the weakest teaching link in the undergraduate education course of optoelectric specialties, thus, has to be reformed.

*wull.0001@163.com; phone86 029-86173335; fax 86 029-86173335

14th Conference on Education and Training in Optics and Photonics: ETOP 2017, edited by Xu Liu,

Xi-Cheng Zhang, Proc. of SPIE Vol. 10452, 104525O - @ 2017 ICO, IEEE, OSA, SPIE

CCC code: $0277-786 X / 17 / \$ 18 \cdot$ doi: $10.1117 / 12.2269777$

Proc. of SPIE Vol. 10452 1045250-1 


\section{BASIC REFORM IDEAS AND CONTENTS}

\subsection{Basic reform idea}

Based on above situations, focusing on the development needs of optical technology, fusing with traditional optical and other multidisciplinary technologies, emphasizing on basic training of engineering abilities, exploration and practice of practical teaching centered on "practice training base" is implemented..

Our basic reform ideas are:

1) Change a single cognitive type internship into a diverse, integrated internship.

2) Make a clear target of the target of "building practice training base and diversifying training contents".

3) Adopt a combination practice teaching mode of on-campus internship base and off-campus enterprise production practices.

4) Off-campus enterprise production practices focus on the learning of advanced management approaches, advanced production processes, and future technological development trends, etc.

5) On-campus internship base focuses on the training of engineering abilities.

\subsection{Reform contents}

\subsubsection{A large number of off-campus enterprise manufacturing internship bases}

Our Optoelectronic specialties continuously attach great importance to the building of practice teaching bases. We have built more than 10 off-campus practice bases in many domestic well-known optical enterprises, such as, Epoch Chemtronics, West Light Group, Jiaozuo Optical Instrument Factory, Xi'an Institute of Optics and Precision Mechanics of CAS, Xi 'an Institute of Applied Optics, etc.

Through off campus enterprise internship practices, students can have an opportunity to learn advanced management approaches, advanced production processes, and future technological development trends, etc. Furthermore, they can also deepening their understandings and cognitions to their own specialties, and make a reasonable professional learning and career planning based on their own conditions.

\subsubsection{Innovative on-campus training}

To achieve the target of "building practice training base and diversifying training contents", on-campus internship base stresses on the training of engineering abilities, which is the main target of the practice teaching.

In this paper, we proposed a new production practice mode of "Using the present laboratory conditions, building the campus internship base". On-campus production practice base is divided into the following five modules: 1) Optical technology and optoelectronic detection; 2) Optical processing and optical detection; 3) Optoelectronic instrument testing; 4) Fiber coupled laser; 5) Optoelectronic innovation practice and training base.

1) Optical technology and optoelectric detection

This module relies on Precision instrument laboratory and Practice base, telescope assembling and tuning, of which, utilizing instruments related to our specialty, such as cameras and telescopes, according the standard enterprise manufacturing process, students are organized to disassemble, assemble, tune, and test. Through the practice training, students can have a knowing of structure designs, assembling processes, testing methods of instruments, and improve their abilities to resolve practical problems.

The students will assemble instruments independently under the guidance of their teachers, and experience the design, assembling and tuning process of instruments like telescope. Through the.assembling process, practical experiences of our students can be enriched, and their independent thinking and practical abilities can also be cultivated.

2) Optical processing and optical detection

The module relies on Optical processing and testing laboratory and Provincial key laboratory of thin film and optical detection, in which, all practice training tasks related to optical processing and testing can be carried out. Combining 
theory and practice, the process knowledge can be talking clearly but cannot be understood easily can be operated to students alively, and deepen their comprehension.

The practice base is composed of 12 different laboratory, such as practice prepare room, spherical precision grinding process room, spherical precision grinding process room, spherical polishing process room, edge grinding process room, coating process room, optical manufacture and testing room, plane manufacturing prepare room, aspheric surface manufacturing room, etc. In the practice base, complete manufacturing process of the spherical and plane optical element devices, such as lenses, prism, planar plates, spherical surface devices, etc., can be implemented. All these optical element devices are the basic components of any optical instrument systems.

\section{3) Optoelectronic instrument testing}

The module relies on the DENSO practice base. Optoelectronic detections, optoelectronic signal identifications, embedded systems developments, and intelligent instrument developments related to practice training activities for undergraduates are implemented in the DENSO practice base. Based on related theoretical curriculums learned by the students, in this module, students will design and develop optoelectronic instruments related to our specialty and have wide applications, such as infrared thermometer. Through actual operation, students can understand and experience the whole process of design, fabrication, welding, assembling, tuning of circuit boards.

\section{4) Fiber coupled laser}

The module relies on the Lab of Fiber Optic Device. Fiber devices are the basic components of fiber optic sensing and fiber optic communications. In the lab, design, fabrication, and testing of source less fiber optic devices, active fiber devices, and optoelectronic detections can be carried out. Basic training contents include: a) Fabrication training of fiber coupled semiconductor laser; b) Fiber fusion training; c) Fabrication training of fiber couplers training; d) Fiber collimator manufacturing training; e) Fiber isolator manufacturing training.

\section{5) Optoelectronic innovation practice and training base}

In this module, optoelectronic innovation practice and training activities related to optoelectronic measurement, optoelectronic detection, and automatic control etc. for undergraduate and graduate students are carried out. The design and innovation process adopts a form of students' independent design under teacher's instruction, through which, innovation of students is encouraged, and they can get an alive experience of the design and creation process of optoelectronic information systems.

Teaching practices carried out in the optoelectronic innovation training base include experiments of related curriculums, open experiments, and production practices for undergraduates.

Experimental contents of related curriculums include optoelectric signal acquisition and processing, basic experiments of the single chip microcomputer (MCU), experiments of FPGA applications, experiments of intelligent car controls, etc.

Open experiments implemented includes intelligent trace finding car design, intelligent tracking car design, intelligent obstacle avoiding car design, design of vehicle avoidance vehicle, quad-rotor unmanned aircraft design, etc.

Production practices for undergraduates includes design of an optoelectronic flame alarms system, design of an infrared remote intelligent vehicle, training of welding and assembling, character display of the cross rotating LED etc.

\subsection{Perfect management system}

In order to achieve a standardized management, a perfect safety management system is established in all our on-campus practice bases, which includes responsibilities of administrators of the production practice base, management system of production practice bases, security system of production practice bases, operation rules of internship practices and so on. The first step of entering into the on-campus internship base is to learn safety rules, rules and regulations. Students are required to obey all the rules and regulations. If there is any violation of the regulations and rules, students will be reeducated, and the corresponding grades will be taken off.

\subsection{Standardized process flow}

In order to achieve integrity, authenticity and practicality of the production practice and training link, exercise students' abilities and improving their comprehensive quality, all the practice and training activities in our production internship bases are required to strictly follow a standardized process flow. For this purpose, according to the practice contents of 
each internship base, a standardized process flow is established correspondingly. Furthermore, each student participating in the practice and training will get a practice handbook, in which all the rules, regulations and process flows, and practice contents are described in details.

At the start of the internship, students should first learn contents of the practice handbook, ,after pass an examination, they can participate the practice and training step in step under management of teachers, through which, they can really get a practical experience on the whole process of real production, fabrication, and tuning of optoelectronic products.

\subsection{Scientific evaluation method}

For the new content and mode of practice, training a scientific evaluation method, is established. Grade evaluation of the production practice includes three parts: usual performance, oral defense and internship report.

Grade of the usual performance are given according attendance, performance, internship diary record of the student, which is accounted for $30 \%$ of the final grade.

After end of the internship, a defense team including guiding teachers and factory technicists will be formed to hear and evaluate related students' oral defense. The defense problems are given according to the real internship contents. The defense grade is accounted for $30 \%$ of the final grade.

After end of the internship, each student must submit an internship report, which should be write according to the internship content and the internship diary. The internship report can fully reflects student's understanding of the production process and equipment, their internship achievement, analysis ability for practical problems. The guiding teacher gives out the corresponding grade, which is accounted for $40 \%$ of the final grade.

\subsection{Effective management mode}

In this kind of internship mode, passive learning of the students is changed into active learning, and their enthusiasm and initiative can be maximally stimulated. This kind of internship mode can provide hands-on opportunities for every student. Students are required to form their internship groups through free combination, which improves their social skills and teamwork abilities.

Every year, guiding teachers are assigned to train in related factory to prepare for the internship.

During the internship process, the guiding teacher, on one hand, according to the practice situation, arranges the internship schedule and organizes lectures, on the other hand, guides the students to do on-site analysis with their theoretical knowledge to resolve typical problems, thorough which, students' abilities to analyze and solve problems can be to cultivated.

\section{REFORM EFFECT}

Under the guidance of the new practice ideas and mode, we set up a on-campus optoelectronic training base, and an optoelectronic innovation practice and training base. These bases cover all the specialties of our optoelectronic engineering college, which fit with orientation of each specialty, and show distinctive features.

(1) Made a beneficial attempt for the building of stable and long-term optoelectronic production practice bases, and proposed an innovative mode of internship;

(2) Reinforce the cultivation of students' abilities to analyze and resolve problems, at the same time, exercise students' practical abilities, teamwork abilities, social work abilities, and strengthen the cultivation of students' abilities of communication and cooperation. The new internship mode has get wide praise from our students;

(3) Effectively utilized and saved the internship funds, a batch of practical training equipment can be reused for a long time were purchased;

(4) Regularly organize guiding teachers to train in enterprises, and from which, theoretical and technical levels of guiding teachers can be improved;

(5) Viewed from the internship effect, internship contents are enriched, the arrangement is more reasonable, performance is improved significantly, which is in a leading position in the field of practice training for our specialties, and has a very good demonstration and a strong promotion value. 
In conclusion, by using the innovation internship mode, under limited funds, we have reasonably resolved the problems in the practical teaching link, and maximized advantages of our resources. At the same time, cultivation of the students' practical skills has been strengthened, which has played a positive role in improving overall quality of students. The innovation internship mode shows a characteristic of reasonable arrangement, substantial content, and outstanding achievements, and the innovation internship mode has a very good demonstration and a strong promotion value. It is also suitable for other engineering specialties, which can further consolidate the foundation, strengthen practical abilities, and cultivate more useful high-quality talents.

\section{REFERENCES}

[1] WANG Xu-chu, LUO Jun. Exploration and Reformation on Practical Teaching of Optoelectronic Information Engineering Specialty. Computer Knowledge and Technology.(7),.1710-1712(2011)

[2] LV Wen-sheng. Work Practice Model Reforming of Engineering Majors in Research University under New Circumstances. Education Teaching Forum. (1),25-28(2017)

[3] Yang Lei, Zhang Shengling, Guo Huishi, Jiao Linjuan.Exploration and Practice of Chemical Production Practice under the Background of "Made in China 2025", 44(4),197-201(2017) 